EPiC Series in Engineering
Volume 3, 2018, Pages 2073-2080
HIC 2018. 13th International
Conference on Hydroinformatics

\title{
Doppler radar data assimilation for mesoscale numerical rainfall prediction
}

\author{
Jiyang Tian ${ }^{1}$, Jia Liu ${ }^{1 *}$, Chuanzhe $\mathrm{Li}^{1}$, and Fuliang $\mathrm{Yu}^{1}$ \\ ${ }^{1}$ State Key Laboratory of Simulation and Regulation of Water Cycle in River Basin, China \\ Institute of Water Resources and Hydropower Research, Beijing, China \\ tjyshd@126.com, hettyliu@126.com, azhe051@163.com, yufl@iwhr.com
}

\begin{abstract}
Hydrological prediction needs high-resolution and accurate rainfall information, which can be provided by mesoscale Numerical Weather Prediction (NWP) models. However, the predicted rainfall is not always satisfactory for hydrological use. The assimilation of Doppler radar observations is found to be an effective method through correcting the initial and lateral boundary conditions of the NWP model. The aim of this study is to explore an efficient way of Doppler radar data assimilation from different height layers for mesoscale numerical rainfall prediction. The Weather Research and Forecasting (WRF) model is applied to the Zijingguan catchment located in semi-humid and semi-arid area of Northern China. Three-dimensional variational data assimilation (3-DVar) technique is adopted to assimilate the Doppler radar data. Radar reflectivity and radial velocity are assimilated separately and jointly. Each type of radar data are divided into seven data sets according to the observation heights: (1) <500m; (2) <1000m; (3) <2000m; (4) 500 1000m; (5) 1000 2000m; (6) >2000m; (7) all heights. Results show that the assimilation of radar reflectivity leads to better results than radial velocity. The accuracy of the predicted rainfall deteriorates as the rise of the observation height of the assimilated radar data. Conclusions of this study provide a reference for efficient utilisation of the Doppler radar data in numerical rainfall prediction for hydrological use.
\end{abstract}

\section{Introduction}

Uncertainty is one of the most crucial problems in many natural sciences, especially in meteorology and hydrology, which makes the prediction of storms and floods worthy of study for meteorologists and hydrologists. NWP systems have been increasingly widely used for high resolution Quantitative Precipitation Forecast (QPF) due to the rapid development of computer

\footnotetext{
* Corresponding author
} 
technology and atmospheric physics (Shrestha, Robertson, Wang, Pagano, \& Hapuarachchi, 2013). Though NWP systems perform well for some meteorological elements, such as temperature, the lowquality initial conditions often cause poor and unreliable rainfall forecasts (Collischonn, Haas, Andreolli, \& Tucci, 2005; Bruno, Cocchi, Greco, \& Scardovi, 2014).

The assimilation of appropriate observations into the NWP system can help improve the initial conditions and even initialize convective-scale events (Sokol, 2009; Liu, Bray, \& Han, 2013). Many research articles indicated that the assimilation of radar data can improve the rainfall forecasts not only for rainfall accumulation but also for rainfall distribution in space and time (Zupanski, Zhang, Zupanski, Hou, \& Cheung, 2011; Sokol, 2011). However, the efficient utilisation of the information provided by weather radar (especially Doppler radar) has not been fully investigated. Radar reflectivity and radial velocity contain different information about the atmosphere. Specifically, reflectivity reflects the amount of cloud water and rain drops per unit volume, while the radial velocity is mainly related to vertical atmospheric motion (Maiello, Ferretti, Gentile, Montopoli, Picciotti, et al, 2014). The question of whether radar reflectivity or radial velocity assimilation has a more significant effect on rainfall forecasts or whether the assimilation of both produces the best results is an interesting issue to explore. In addition, the assimilation of too much data without controlling the data quality and redundancy may cause a variable conflict in the WRF model and lead to non-convergence or deterioration of the rainfall products. In this case, the assimilation of all obtainable radar reflectivity and radial velocity data from all scan elevations does not guarantee the best assimilation results.

In this study, radar reflectivity and radial velocity from Doppler radar are assimilated separately and jointly into the WRF model via the 3-DVar technique to examine the improvements in the rainfall forecast. Radar observations from different scan elevations are grouped into 7 data sets according to their observation heights: (1) data below $500 \mathrm{~m}$, (2) data below $1000 \mathrm{~m}$, (3) data below $2000 \mathrm{~m}$, (4) data between $500 \mathrm{~m}$ and $1000 \mathrm{~m},(5)$ data between $1000 \mathrm{~m}$ and $2000 \mathrm{~m}$, (6) data above $2000 \mathrm{~m}$, and (7) data from all scan elevations. A storm event that occurred on 21 July 2012 over the "Jing-Jin-Ji" (Beijing-Tianjin-Hebei) Region of Northern China received a widespread attention due to its high rain intensity and substantial flood damage. During the storm, rainfall accumulated in a small upstream mountainous catchment, named Zijingguan, which is selected to be forecasted in the study. Radar reflectivity and radial velocity from different observation heights are assimilated separately or jointly to investigate the most efficient utilisation of the radar-detected information for numerical rainfall forecast.

\section{Material and methods}

\subsection{WRE model setup and 3-DVar data assimilation}

The WRF model is used to downscale the Global Forecast System (GFS) forecast data with resolution of $1 \times 1^{\circ}$ to finer horizontal resolutions. Two nested domains are used, with the grid spacing of the inner domain set to $3 \mathrm{~km}$ and the downscaling ratio set to $1: 3$. The domain sizes are $1260 \times 1260$ $\mathrm{km}^{2}$ and $450 \times 360 \mathrm{~km}^{2}$ for the outer and the inner domain. With the top level set at $50 \mathrm{hPa}$, the two domains are comprised of 40 vertical pressure levels. The most extensively used parameterizations that perform generally well in Northern China are adopted: WSM6 for microphysics, RRTM for longwave radiation, Dudhia for short-wave radiation, Noah for LSM, MYJ for PBL, and KF for cumulus physics (Di, Duan, Gong, Wang, Gan, et al, 2015). The time step of the WRF model output is set to one hour. In order to seek an optimal estimate of the true atmospheric state, the WRF-3DVar data assimilation system is used in tandem with WRF for assimilating the radar data in real-time (Barker, Huang, Guo, Bourgeois, \& Xiao, 2004). The default NCEP global statistical BE provided by the 
WRF-3DVar system, CV3, is used in this study since it has a wide applicability and can be used for any regional domain (Meng \& Zhang, 2008). The rainwater mixing ratio is chosen as the moisture control variable instead of the pseudo-relative humidity when assimilating the radar reflectivity. For the assimilation of the radial velocity, the preconditioned wind control variables were also combined with the rainwater mixing ratio (Sun \& Crook, 1997).

\subsection{Study area and storm event}

The Zijingguan catchment is located in the Daqing river basin of Northern China. It has a drainage area of $1760 \mathrm{~km}^{2}, 54 \mathrm{~km}$ long from north to south and $61 \mathrm{~km}$ wide from east to west. The catchment has a temperate continental monsoon climate. The average annual rainfall is approximately $600 \mathrm{~mm}$, and the majority of rain falls during the flood season from late May to early September. Its previous history of extreme storms and floods make the Zijingguan catchment a representative in the semihumid and semi-arid area of Northern China that requires flood warnings. Figure 1 shows the relative positions of the Zijingguan catchment, the nested WRF domains, the radar scan area and the image of radar reflectivity. A $24 \mathrm{~h}$ storm event that occurred over the Beijing-Tianjin-Hebei region on 21 July 2012 is chosen to be reproduced in the Zijingguang catchment. Because of the high intensity rainfall, wide coverage and significant losses, the storm event has received widespread attention in China. The observed $24 \mathrm{~h}$ rainfall accumulation was $172 \mathrm{~mm}$ in the catchment, and the peak flow reached 2580 $\mathrm{m}^{3} / \mathrm{s}$ at the catchment outlet. Many studies have investigated the reasons that triggered the storm event (Zhong, Mu, Zhang, Zhao, Zhang, et al, 2015). The main reasons for the heavy storm are that the eastward-moving cold vortex in the mid-high troposphere met the northward-moving subtropical high over the region (Guo, Xiao, Yang, \& Tang, 2015). Two phases can be found in the storm event: 1. the strong convective rain took place in warm sector, ahead of the cold front; 2 . the frontal rain is dominated after the arriving of the cold front. The observed areal rainfall is calculated by the Thiessen polygon method with the observed data of 11 rain gauges. The areal rainfall forecast from the WRF is calculated by the grid cells which have more than $50 \%$ area located inside the Zijingguan catchment.

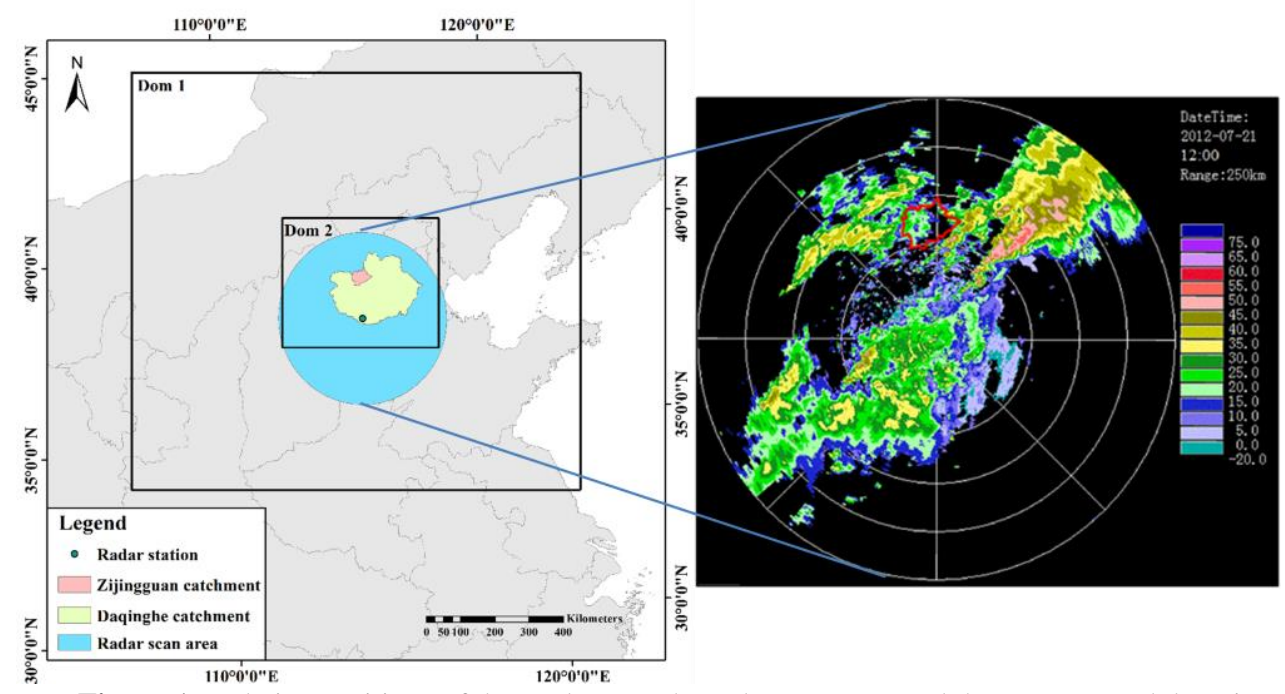

Figure 1: Relative positions of the study area, the radar coverage and the WRF nested domains

The storm event began at 03:00 on 21 July 2012 and ended at 03:00 on 22 July 2012. Cycling WRF runs are adopted to continuously assimilate radar observations via 3-Dvar. To obtain the complete rainfall process using the WRF model, the running time is set to be $36 \mathrm{~h}$, which is longer than the duration $(24 \mathrm{~h}$ ) of the storm event. As illustrated by Figure 2, run1 is the initial WRF run 
without data assimilation. The first $6 \mathrm{~h}$, which is represented by a dashed line segment, is for the model spin-up. Data assimilation starts on 21/07/2012 at 00:00 and occurs with an interval of $6 \mathrm{~h}$. Run2, run3, run4, run5 and run6 are executed every $6 \mathrm{~h}$ to show the rainfall improvement for the entire storm duration by each time of radar data assimilation. The first guess file generated in the previous run is used to provide the initial conditions for the following run (Liu, Bray, \& Han, 2013).

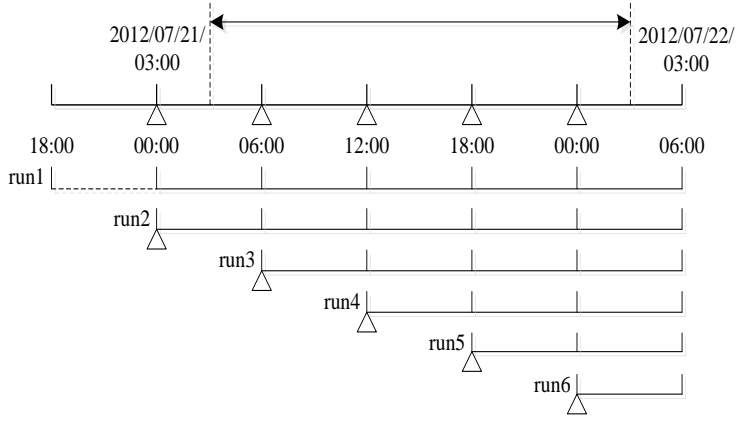

Figure 2: Time bars of the cycling WRF-3DVar runs

\subsection{Doppler radar data and assimilation scenario design}

The Zijingguan catchment is completely covered by an S-band Doppler weather radar, which is located approximately $100 \mathrm{~km}$ from the catchment and covers an area with a radius of $250 \mathrm{~km}$. Radar reflectivity and radial velocity from 9 scan elevations $\left(0.5^{\circ}, 1.5^{\circ}, 2.4^{\circ}, 3.4^{\circ}, 4.3^{\circ}, 6.0^{\circ}, 9.9^{\circ}, 14.6^{\circ}\right.$, and $19.5^{\circ}$ ) are obtained circularly every $0.1 \mathrm{~h}$. The radar data are provided by the newest generation weather radar network of China (CINRAD/SC). Before the radar data are assimilated in WRF-3DVar, ground clutter, radial interference echo, speckles and other artefacts are removed through the procedure of quality control, which is supported by China Integrated Meteorological Information Service System (CIMISS) of China Meteorological Administration. Reflectivity and radial velocity data are assimilated with observation error standard deviations specified as $2 \mathrm{dBZ}$ and $1 \mathrm{~m} / \mathrm{s}$, respectively. Radial velocity data are assimilated only when the observed reflectivity is larger than 10 dBZ (Tong \& Xue, 2005).

To explore the most efficient assimilation of the radar data for rainfall forecasts, observations of both radar reflectivity and radial velocity are grouped into 7 data sets according to their observation heights: (1) <500 m, (2) <1000 m, (3) <2000 m, (4) 500 1000 m, (5) 1000 2000 m, (6) >2000 m, and (7) all layers. Radar reflectivity and radial velocity from each data set are assimilated separately and jointly, which results in $7 \times 3$ scenarios.

\section{Results and discussion}

The cumulative curves of the WRF forecasted areal rainfall in the Zijingguan catchment are shown in Figure 3 Figure 9 for the $7 \times 3$ data assimilation scenarios. Each figure contains three data assimilation scenarios for the assimilation of (a) reflectivity, (b) radial velocity and (c) both reflectivity and radial velocity. In each single subfigure, the black solid curve represents the observation of the rain gauges and the gray area indicates the duration of the $24 \mathrm{~h}$ storm event. The accumulation of the forecasted rainfall from the six WRF runs is represented by colored curves, with the first $6 \mathrm{~h}$ being solid, and the rest being dashed. The dashed curve segment means the forecasts are 

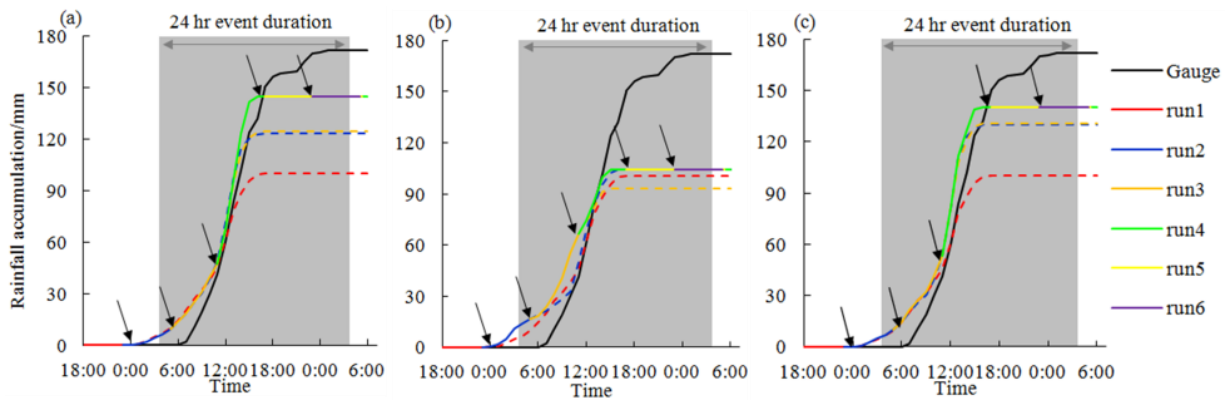

Figure 3: Assimilation results $(<500 \mathrm{~m})$ : (a) reflectivity; (b) velocity; (c) reflectivity and velocity
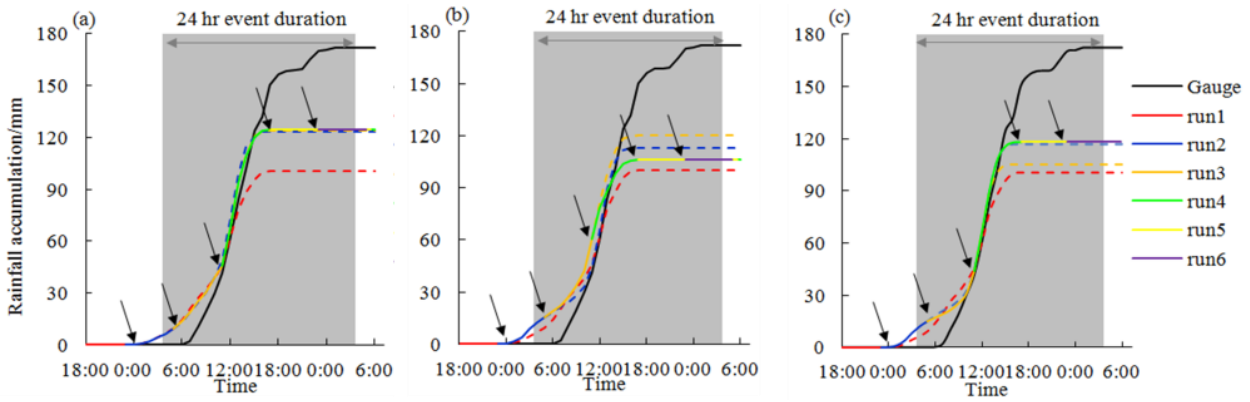

Figure 4: Assimilation results $(<1000 \mathrm{~m})$ : (a) reflectivity; (b) velocity; (c) reflectivity and velocity
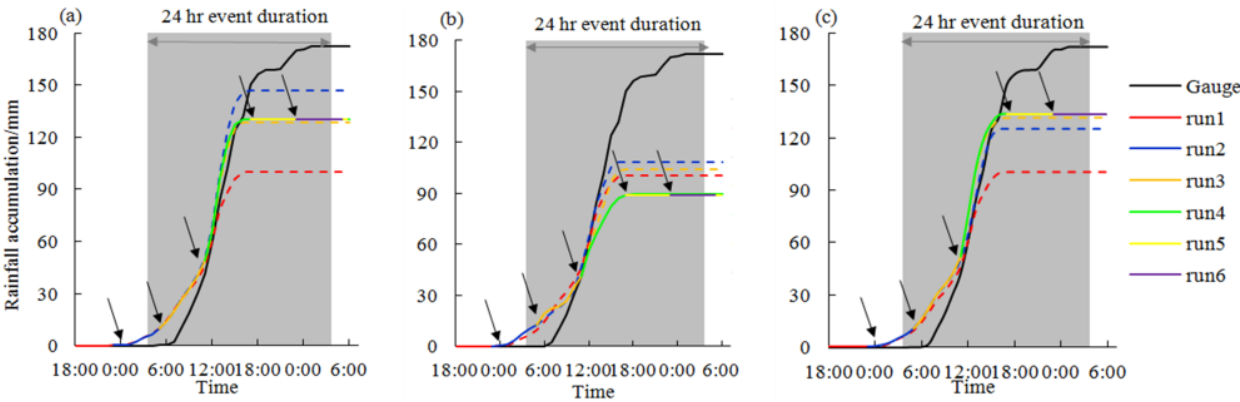

Figure 5: Assimilation results (<2000m): (a) reflectivity; (b) velocity; (c) reflectivity and velocity
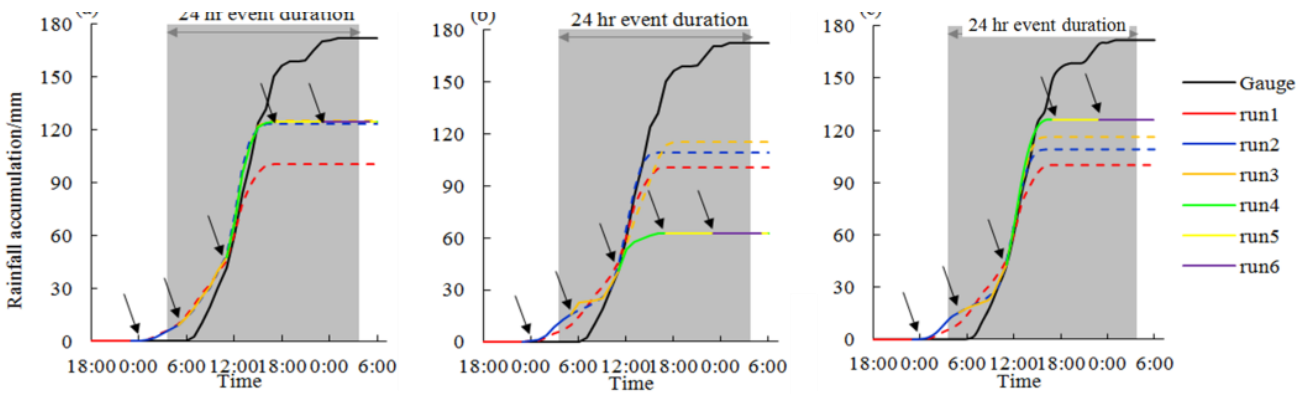

Figure 6: Assimilation results (500 1000m): (a) reflectivitv: (b) velocitv: (c) reflectivitv and velocitv

no longer the latest because the next run with new data assimilation has been activated. The black arrows point out the starting times of the six runs. It is expected that the cumulative curve of the forecasted rainfall would gradually become closer to the ground truth after each time of data assimilation. 

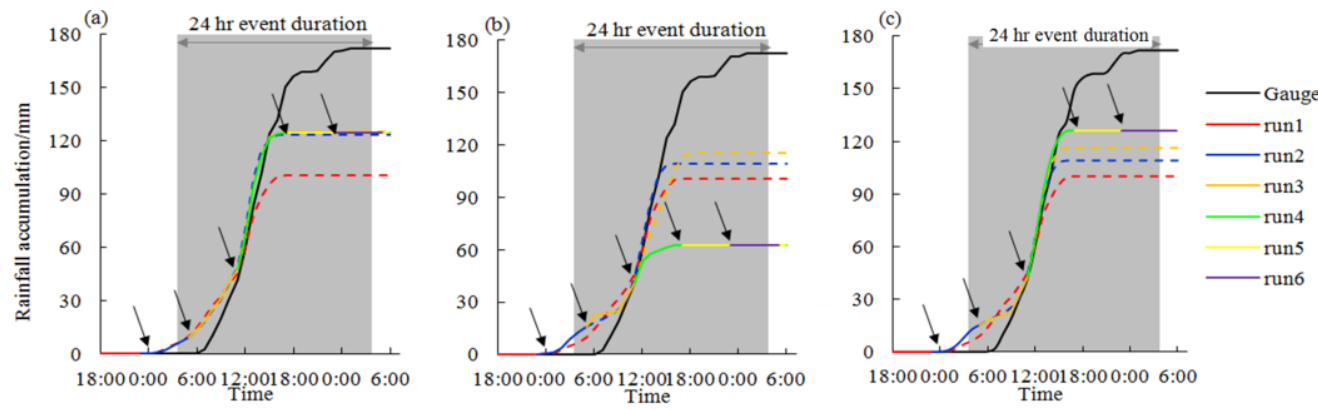

Figure 7: Assimilation results (1000 2000m): (a) reflectivity; (b) velocity; (c) reflectivity and velocity
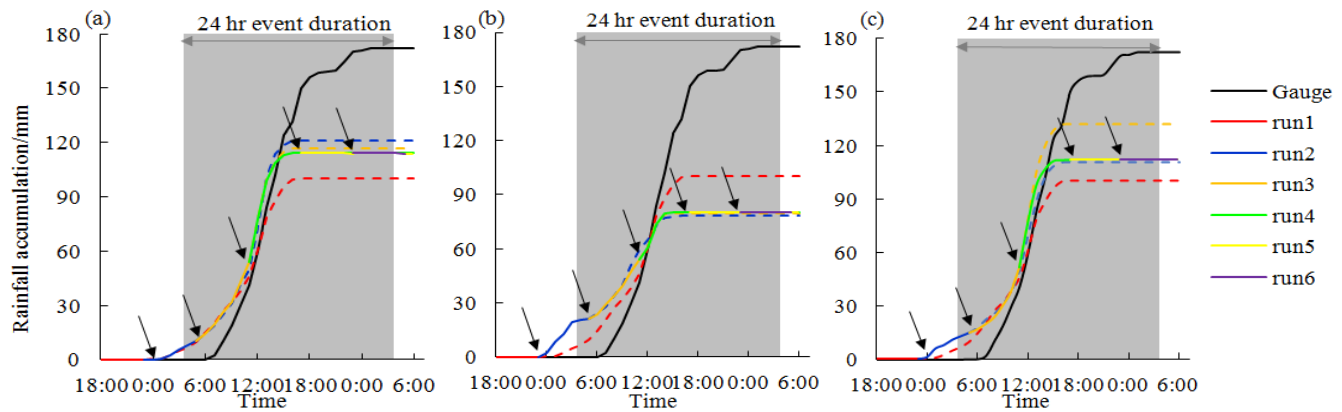

Figure 8: Assimilation results (>2000m): (a) reflectivity; (b) velocity; (c) reflectivity and velocity
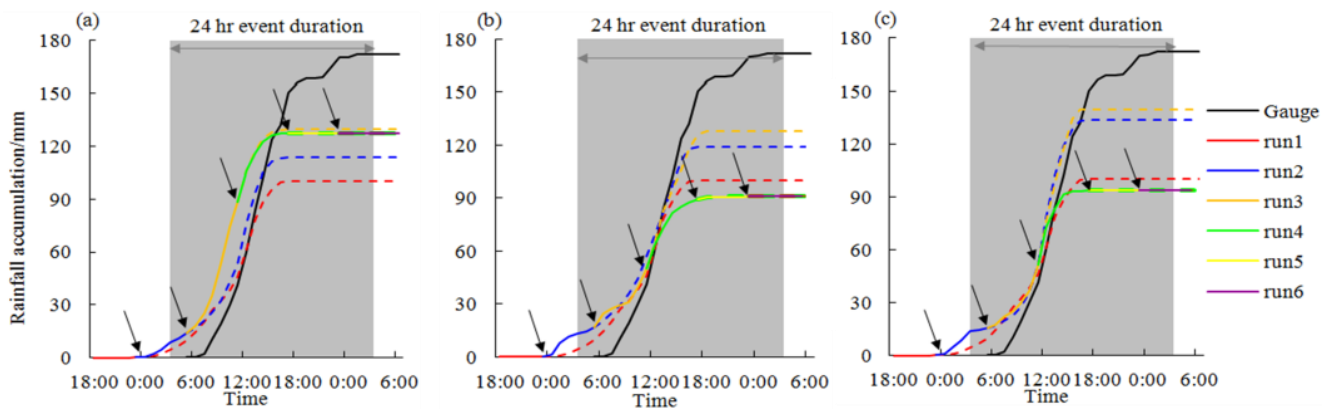

Figure 9: Assimilation results (all layers): (a) reflectivity; (b) velocity; (c) reflectivity and velocity

The performance of assimilating both types of radar data (reflectivity and radial velocity) are somewhere in between, better than radial velocity assimilation but worse than reflectivity assimilation. In assimilating radar reflectivity or both types of radar data, it is interesting to observe that the higher layers come from the assimilated radar reflectivity or both types of radar data, the less improvements are found with the rainfall forecasts. It indicates that the assimilation of data with a lager elevation range can not always guarantee better results. Radar reflectivity assimilation $<500 \mathrm{~m}$ shows the best rainfall forecasts out of the 21 assimilation scenarios. In addition, the involvement of radar reflectivity or both types of radar data in higher layers may sometimes reduce the effect of rainfall improvements. For assimilating radial velocity, there is no clear conclusion. This might be related to the relatively large errors in the radial velocity observations and also the data assimilation frequency (Lin, Lin, Xiao, \& Kuo, 2011). In all the 21 assimilation scenarios, most of the forecasted rainfall comes from run3 (starts at 21/07/2012 06:00 and ends at 21/07/2012 12:00) and run4 (starts at 21/07/2012 12:00 and ends at 21/07/2012 18:00). It can also be observed that the forecasted storms start and end earlier than the observations with shorter durations for the assimilation results of all the scenarios. 
The accumulated areal rainfall for the $24 \mathrm{~h}$ storm duration and the relative errors are calculated for all the scenarios, shown in Table 1. The assimilation of radar reflectivity is the best choice for the forecast rainfall, which can be improved by 7.72 26.17\% for different layers compared with the results without data assimilation. The assimilation of radial velocity with the relative errors of 68.49 -43.35\% always performs worse than the original run. Although the assimilation of both radar reflectivity and radial velocity can improve the rainfall forecasts, except when assimilation happens with data from all layers, the improvements are less obvious than assimilating only the radar reflectivity. Therefore, to obtain more accurate rainfall and to improve the assimilation efficiency of radar data, assimilating only radar reflectivity with heights $<500 \mathrm{~m}$ is a good choice for operational rainfall forecasts. The reflectivity can represent the number of cloud water and rain drops per unit volume. During the storm event, more water vapor is distributed in lower layers, and the raindrops can also be easily captured by Doppler radar.

\begin{tabular}{lrrrrr}
\hline $\begin{array}{l}\text { Data } \\
\text { set }\end{array}$ & Elevation & Original run & \multicolumn{2}{r}{ Data assimilation run } \\
\cline { 3 - 6 } & & & Reflectivity & Velocity & $\begin{array}{r}\text { Reflectivity }+ \\
\text { velocity }\end{array}$ \\
\hline 1 & $<500 \mathrm{~m}$ & $95.54(-44.51)$ & $140.60(-18.34)$ & $93.05(-45.95)$ & $135.60(-21.24)$ \\
2 & $<1000 \mathrm{~m}$ & $95.54(-44.51)$ & $120.09(-30.25)$ & $97.54(-43.35)$ & $109.54(-36.38)$ \\
3 & $<2000 \mathrm{~m}$ & $95.54(-44.51)$ & $125.90(-26.88)$ & $81.80(-52.49)$ & $128.50(-25.37)$ \\
4 & $500 \sim 1000 \mathrm{~m}$ & $95.54(-44.51)$ & $119.95(-30.33)$ & $54.26(-68.49)$ & $117.52(-31.74)$ \\
5 & $1000 \sim 2000 \mathrm{~m}$ & $95.54(-44.51)$ & $117.64(-31.67)$ & $87.74(-49.04)$ & $113.58(-34.03)$ \\
6 & $>2000 \mathrm{~m}$ & $95.54(-44.51)$ & $108.84(-36.78)$ & $60.85(-64.66)$ & $100.90(-41.39)$ \\
7 & all layers & $95.54(-44.51)$ & $118.92(-30.93)$ & $77.65(-54.90)$ & $79.76(-53.67)$ \\
\hline
\end{tabular}

Table 1: $24 \mathrm{~h}$ rainfall accumulations $(\mathrm{mm})$ and relative errors $(\%)$ of the assimilation scenarios

\section{Conclusion}

This study explores the effect of radar data assimilation from different height layers using WRF3DVar for rainfall forecast in the "Jing-Jin-Ji" Region of Northern China. Results show that the assimilation of radar reflectivity can help improve the forecasts of the accumulated rainfall, although the improvement effect decreases with the increase of the observation height. However, the assimilation of radar velocity always performs worse than the original rainfall forecasts without data assimilation. It can also be found that the starting and ending times of storm event are not accurately forecasted by all scenarios in this study, in which case it might lead to bad applications of the rainfall products, i.e., flood warnings may be issued at wrong time. The assimilation of traditional meteorological observations and satellite remote sensing data, together with the increase of the data assimilation frequency, may help further improve the NWP rainfall forecasts for hydrological use.

\section{Acknowledgements}

This study was supported by the National Key Research and Development Program (Grant No. 2017YFC1502405, 2016YFA0601503), the Major Science and Technology Program for Water Pollution Control and Treatment (Grant No. 2018ZX07110001), the Hebei Province Water Scientific Research Project (Grant No. 2015-16), and the IWHR Research \& Development Support Program (Grant No. WR0145B732017). 


\section{References}

Barker, D., Huang, W., Guo, Y., Bourgeois, A., \& Xiao, Q. (2004). A three-dimensional variational data assimilation system for MM5: implementation and initial results. Monthly Weather Review, 132, pp. 897-914.

Bruno, F., Cocchi, D., Greco, F., \& Scardovi, E. (2014). Spatial reconstruction of rainfall fields from rain gauge and radar data. Stochastic Environmental Research and Risk Assessment, 28, pp. $1235-1245$.

Collischonn, W., Haas, R., Andreolli, I., \& Tucci, C. (2005). Forecasting River Uruguay flow using rainfall forecasts from a regional weather-prediction model. Journal of Hydrology, 305, pp. 87-98.

Di, Z., Duan, Q., Gong, W., Wang, C., Gan, Y., Quan, J., . . Miao, C. (2015). Assessing WRF model parameter sensitivity: A case study with 5 day summer precipitation forecasting in the Greater Beijing Area. Geophysical Research Letters, 42, pp. 579-587.

Guo, C., Xiao, H., Yang, H., \& Tang, Q. (2015). Observation and modeling analyses of the macro-and microphysical characteristics of a heavy rain storm in Beijing. Atmospheric Research, 156, pp. 125-141.

Lin, H., Lin, P., Xiao, Q., \& Kuo, Y. (2011). Effect of Doppler radial velocity data assimilation on the simulation of a typhoon approaching Taiwan: A case study of Typhoon Aere (2004). Terrestrial Atmospheric and Oceanic Sciences, 22, pp. 325-345.

Liu, J., Bray, M., \& Han, D. (2013). A study on WRF radar data assimilation for hydrological rainfall prediction. Hydrology and Earth System Sciences, 17, pp. 3095-3110.

Liu, J., Bray, M., \& Han, D. (2013). Exploring the effect of data assimilation by WRF-3DVar for numerical rainfall prediction with different types of storm events. Hydrological Processes, 27, pp. 3627-3640.

Maiello, I., Ferretti, R., Gentile, S., Montopoli, M., Picciotti, E., Marzano, F., \& Faccani, C. (2014). Impact of radar data assimilation for the simulation of a heavy rainfall case in central Italy using WRF-3DVAR. Atmospheric Measurement Techniques, 7, pp. 2919-2935.

Meng, Z., \& Zhang, F. (2008). Tests of an ensemble Kalman filter for mesoscale and regional-scale data assimilation. Part III: Comparison with 3DVAR in a real-data case study. Monthly Weather Review, 136, pp. 522-540.

Shrestha, D., Robertson, D., Wang, Q., Pagano, T., \& Hapuarachchi, H. (2013). Evaluation of numerical weather prediction model precipitation forecasts for short-term streamflow forecasting purpose. Hydrology and Earth System Sciences, 17, pp. 1913-1931.

Sokol, Z. (2009). Effects of an assimilation of radar and satellite data on a very short range forecast of heavy convective rainfalls. Atmospheric Research, 93, pp. 188-206.

Sokol, Z. (2011). Assimilation of extrapolated radar reflectivity into a NWP model and its impact on a precipitation forecast at high resolution. Atmospheric Research, 100, pp. 201-212.

Sun, J., \& Crook, N. (1997). Dynamical and microphysical retrieval from Doppler radar observations using a cloud model and its adjoint. Part I: Model development and simulated data experiments. Journal of the Atmospheric Sciences, 54, pp. 1642-1661.

Tong, M., \& Xue, M. (2005). Ensemble Kalman filter assimilation of Doppler radar data with a compressible nonhydrostatic model: OSS Experiments. Monthly Weather Review, 133, pp. 1789-1807.

Zhong, L., Mu, R., Zhang, D., Zhao, P., Zhang, Z., \& Wang, N. (2015). An observational analysis of warm-sector rainfall characteristics associated with the 21 July 2012 Beijing extreme rainfall event. Journal of Geophysical Research Atmospheres, 120, pp. 3274-3291.

Zupanski, D., Zhang, S., Zupanski, M., Hou, A., \& Cheung, S. (2011). A prototype WRF-Based ensemble data assimilation system for dynamically downscaling satellite precipitation observations. Journal of Hydrometeorology, 12, pp. 118-134. 